\title{
Adsorptive desulfurization of feed diesel using chemically impregnated coconut coir waste
}

\author{
Md. J. K. Ahmed • M. Ahmaruzzaman
}

Received: 25 January 2014/Revised: 6 May 2014/ Accepted: 12 July 2014/Published online: 25 July 2014

(C) Islamic Azad University (IAU) 2014

\begin{abstract}
This study reports the usage of chemically impregnated coconut coir waste (CICCW) as a low-cost adsorbent for the desulfurization of feed diesel. The characterization of the developed adsorbent was focused on quantitative analysis (carbon yield \%, proximate, ultimate, carbon surface functionalities, BET surface area and porosity distribution, and particle size analysis), qualitative analysis (FTIR), and optical analysis (SEM). Batch experiments with feed diesel having a total sulfur concentration of 2,050 $\mathrm{mg} \mathrm{L}^{-1}$ were conducted to optimize the adsorption parameters such as adsorbent dose, temperature, and contact time. The adsorption process shows an optimum dose of $1 \mathrm{~g} / 20 \mathrm{~mL}$, and the equilibrium is attained in $3 \mathrm{~h}$. The adsorption of sulfur onto the adsorbent at optimum temperature $293 \mathrm{~K}$ is regulated by external mass transfer (diffusion into mesopores) followed by a steady adsorption phase with intra-particle diffusion in micropores. A Fickian mechanism controls the diffusion of sulfur molecules from the solution onto the surface of the adsorbent. Freundlich adsorption isotherm illustrates the equilibrium adsorption data very well. The negative value of $\Delta G^{\circ}\left(-27.61 \mathrm{~kJ} \mathrm{~mol}^{-1}\right)$ and $\Delta S^{\circ}\left(-44.56 \mathrm{~J} \mathrm{~K}^{-1} \mathrm{~mol}^{-1}\right)$ indicates the feasibility, spontaneity of the adsorption process and justified the decrease in the randomness of adsorbed sulfur molecules onto the adsorbent surface, respectively. The exhausted $\mathrm{CICCW}$ can be effectively regenerated by methanol and reutilized for three
\end{abstract}

Electronic supplementary material The online version of this article (doi:10.1007/s13762-014-0654-4) contains supplementary material, which is available to authorized users.

Md. J. K. Ahmed · M. Ahmaruzzaman ( $\square)$

Department of Chemistry, National Institute of Technology

Silchar, Silchar 788010, Assam, India

e-mail: md_a2002@rediffmail.com adsorption-desorption cycles. The approximate cost of preparation of the adsorbent was USD 10.714 per $\mathrm{kg}$. These results clearly proved the feasibility of the developed lowcost adsorbent (CICCW) as a good candidate for the desulfurization of feed diesel.

Keywords Adsorption - Sulfur - Batch experiments . Freundlich isotherm

\section{Introduction}

Desulfurization of diesel fuel is gaining worldwide interest among the researchers. This is due to stern regulations and fuel specifications adopted in many countries for checking environmental pollution caused by automobile exhaust gases (Zhao et al. 2010). The regulations projected that the upper limit of sulfur concentration in diesel can be reduced from 500 to $15 \mathrm{mg} \mathrm{L}^{-1}$ in USA, $50-10 \mathrm{mg} \mathrm{L}^{-1}$ in EU, 30-10 $\mathrm{mg} \mathrm{L}^{-1}$ in Korea (Park et al. 2008), and $350 \mathrm{mg} \mathrm{L}^{-1}$ in India. Low-sulfur fuel finds its application in fuel cell system. Fuel cell is one of the most potential and suitable energy conversion devices for generating electricity for both mobile vehicles and stationary power plants including residential applications (Song 2002). In hydrocarbon-based fuel cell system, the catalysts used such as reforming catalysts and water-gas-shift catalysts are poisoned by the $\mathrm{H}_{2} \mathrm{~S}$ produced. For automotive and military use, diesel is the ideal fuel as it has high energy density, readily available, and safe for transportation and storage. But the commercial diesel fuel usually contains certain refractory sulfur compounds (Sarda et al. 2012) viz. benzothiophene (BT), dibenzothiophene (DBT), and 4,6dimethyldibenzothiophene (DMDBT), which causes environmental pollution. In an internal combustion engine, 
these sulfur compounds are combusted to produce $\mathrm{SO}_{x}$ that contributes to the formation of acid rain. This restrains the exploitation of advanced technology to check total pollutant emissions including $\mathrm{NO}_{x}, \mathrm{HC}, \mathrm{CO}$, and particulate matter.

Hydrodesulfurization (HDS) is the conventional method (adopted by refineries) for removing organic sulfur in diesel, gasoline, and other intermediate distillates by using $\mathrm{Co}-\mathrm{Mo} /$ $\mathrm{Al}_{2} \mathrm{O}_{3}$ or $\mathrm{Ni}-\mathrm{Mo} / \mathrm{Al}_{2} \mathrm{O}_{3}$ as catalysts. The efficiency of HDS can be increased by the use of higher temperatures and pressures, more dynamic catalysts, or longer residence times (Babich and Moulijn 2003). Under these conditions, a part of olefins and aromatics contained in the fuels is saturated and as a consequence the octane number decreases substantially, which is unfavorable. Nevertheless, these choices are expensive to refineries. These motivate extensive research work in substituting traditional technologies or additional desulfurization technologies for diesel fuels.

One of the promising approaches to phase out these problems is adsorptive desulfurization (ADS). It is advantageous because it can be executed at ambient temperature and pressure exclusive of hydrogen or oxygen consumption. Moreover, adsorbents can be reclaimed by appropriate regeneration and reutilized. The widely used and efficient adsorbent is the commercial activated carbon (CAC), but its usage comes with high expense. This motivates the use of alternative low-cost adsorbents for the desulfurization of diesel. The viability of adsorbents such as CAC (Jiang et al. 2003; Zhou et al. 2009), zeolites (Xiao et al. 2008), mesoporous materials (Subhan and Liu 2011), carbon nanoparticles (Fallah and Azizian 2012), metal-organic frameworks (Khan and Jhung 2013; Achmann et al. 2010), activated carbon cloth (Fallah and Azizian 2014), and nano-porous activated carbon (Triantafyllidis and Deliyanni 2014) has been explored by researchers for the desulfurization of diesel/model fuels/liquid fuels. The denitrogenation of diesel feedstock such as straight run gas oil (SRGO), coker gas oil (CGO), and light cycle oil (LCO) toward adsorptive desulfurization of diesel has also been tried by many researchers. Various nitrogen-containing compounds such as carbazole, indole, quinoline, and pyridine types of compounds are also removed along with sulfur compounds from the diesel feedstock during the adsorption process (Whitehurst et al. 2000; Laredo et al. 2013).

The overall objective of this work was to investigate the desulfurization of feed diesel by using adsorption technology. The approach is focused on laboratory prepared low-cost adsorbent obtained by $\mathrm{H}_{3} \mathrm{PO}_{4}$ impregnation of coconut coir waste for removal of sulfur from feed diesel. This is achieved by conducting ADS of real feed diesel, examining the adsorptive performance, and cost estimation of the developed adsorbent. To the best of knowledge of the authors, $\mathrm{H}_{3} \mathrm{PO}_{4}$ impregnated coconut coir waste has not been utilized for the desulfurization of feed diesel (from refineries) in particular with high sulfur concentration above $2,000 \mathrm{mg} \mathrm{L}^{-1}$. This research work was carried out on July'2013 at National Institute of Technology Silchar and Indian Oil Corporation Limited, Guwahati Refinery.

\section{Materials and methods}

\section{Materials}

All the chemicals and reagents used in this study were of analytical reagent (AR) grade. The feed diesel (adsorbate) examined in the present work was supplied by the Indian Oil Corporation Ltd., Guwahati Refinery before undergoing hydrodesulfurization. Coconut coir wastes were collected from nearby rural areas of NIT Silchar.

Material development

The adsorbent used in this study was prepared by chemical impregnation of coconut coir waste using $\mathrm{H}_{3} \mathrm{PO}_{4}$. The waste was first cleansed with distilled water to get rid of dirt and dried in a hot air oven at $383 \mathrm{~K}$ for $5 \mathrm{~h}$. This is followed by $\mathrm{H}_{3} \mathrm{PO}_{4}$ impregnation at $373 \mathrm{~K}$ for $1 \mathrm{~h}$ in a hot plate. The treated waste is then carbonized at $873 \mathrm{~K}$ for $1 \mathrm{~h}$ in a muffle furnace under nitrogen atmosphere. Finally, the carbonized product is washed with distilled water until the $\mathrm{pH}$ of the washings reached $\sim 7$. It is evident that lingocellulosic materials are preferred for chemical activation (Jagtoyen and Derbyshire 1993), particularly with $\mathrm{H}_{3} \mathrm{PO}_{4}$, and as the precursor has cellulosic component; $\mathrm{H}_{3} \mathrm{PO}_{4}$ has been selected for the impregnation. The idea of activation is to augment the adsorption efficiency in addition to carbonizing the coconut coir waste. The adsorbent thus produced was kept in an oven at $383 \mathrm{~K}$ for $6 \mathrm{~h}$ to get rid of any moisture trapped within the adsorbent pores. The adsorbent was finely ground for use in adsorption and stored in desiccator till further use. The adsorbent thus developed is referred to as chemically impregnated coconut coir waste and henceforth abbreviated as CICCW.

The percentage of carbon yield of the adsorbent was calculated by the following equation:

Carbon yield $(\%)=\frac{\text { Wt. after carbonisation }(\mathrm{g})}{\text { Wt. before carbonisation }(\mathrm{g})} \times 100$

Characterization of developed adsorbent

The physical and chemical analyses of CICCW were performed as per ASTM standard (American Standard for Testing and Materials). Macro analysis or Proximate 
analysis of the adsorbent encompasses the determination of moisture content, volatile matter, ash, and fixed carbon content as wt\% (as received) as per ASTM D-3172, using a hot air oven and a muffle furnace. Ultimate analysis or microanalysis (ASTM D-3176) includes determination of carbon, hydrogen, and nitrogen content as wt\% (dry ashfree basis), which was done by a Perkin Elmer PR 2400 series II CHN Analyzer. The texture and morphology of the adsorbent were examined by a Scanning Electron Microscope (SEM Leo $1430 \mathrm{VP}$ ). FTIR analysis of the CICCW sample was performed on a Nicolet Impact I-410 FTIR Spectrophotometer. A Micromeritics, A SAP 2010 Surface Area Analyzer was used to determine the textural features of the adsorbent. $\mathrm{N}_{2}$ adsorption isotherm was used to find out the pore size distribution and Brunauer-Emmett-Teller (BET) surface area by using the Brunauer et al. equation (1938). BJH (Barret-Joyner-Halenda) desorption method was used to calculate the average pore diameter and cumulative volume of the pores. The particle size analysis of the adsorbent was done on a Malvern Mastersizer 2000. Boehm titration has been adopted for identifying oxygen surface functional groups, such as carboxyl (R-COOH), lactone (R-OCO), and phenol (R-OH) for the adsorbent (Boehm 1996). The procedure for performing Boehm titration is in accordance with standardized method (Sarah et al. 2010) described in detail in the supporting information.

The amounts of acidic groups on the CICCW surface were determined by Eq. 2

$n_{\mathrm{CSF}}=\frac{n_{\mathrm{HCl}}}{n_{\mathrm{B}}}[\mathrm{B}] V_{\mathrm{B}}-\left([\mathrm{HCL}] V_{\mathrm{HCl}}-[\mathrm{NaOH}] V_{\mathrm{NaOH}}\right) \frac{V_{\mathrm{B}}}{V_{\mathrm{a}}}$

The amount of basic groups on the surface of CICCW was computed by Eq. 3

$n_{\mathrm{CSF}}=[\mathrm{B}] V_{\mathrm{B}}-\left([\mathrm{HCL}] V_{\mathrm{HCl}}\right) \frac{V_{\mathrm{B}}}{V_{\mathrm{a}}}$

where $n_{\mathrm{CSF}}$ refers to the moles of carbon surface functionalities on the surface of the carbon that reacts with the base during the mixing step; [B] and $V_{\mathrm{B}}$ are the concentration and volume of the reaction base; $V_{\mathrm{a}}$ is the volume of the aliquots taken from $V_{\mathrm{B}} ;[\mathrm{HCl}]$ and $V_{\mathrm{HCl}}$ are the concentration and volume of the acid added to the aliquot.

\section{Adsorption assay}

The experiments were carried out in a batch system by shaking $20 \mathrm{~mL}$ feed diesel (sulfur concentration 2,050 $\left.\mathrm{mg} \mathrm{L}^{-1}\right)$ with pre-weighed $(0.2-1.2 \mathrm{~g})$ dried amount of adsorbent in $100 \mathrm{~mL}$ Erlenmeyer flask (with stopper) under controlled parameters of adsorption to study the effect of adsorbent dose, temperature, contact time, and adsorption isotherm. The samples were withdrawn at preset time interval and filtered through Whatmann No. 42 filter paper, and the filtrate was examined for residual sulfur concentration.

Analysis of sulfur in liquid phase

The sulfur concentration in the feed diesel was measured by an Oxford XRF Sulfur in Oil Analyzer as per ASTM D 4294. The test sample is placed in the beam from an X-ray source. The resultant excited characteristic radiation is measured, and the accumulated count is compared with a calibration graph/curve or equation plotting counts against sulfur content in $\mathrm{mg} \mathrm{L}^{-1}$, as a series of calibration samples covering range of sulfur content under examination. The percentage removal and adsorption uptake of sulfur were estimated by the following equations:

Percentage removal of sulfur $=\frac{\left(C_{\mathrm{o}}-C_{\mathrm{e}}\right)}{C_{\mathrm{o}}} \times 100$

Adsorptive uptake of sulfur per g of adsorbent;

$$
q_{\mathrm{e}}=\frac{\left(C_{\mathrm{o}}-C_{\mathrm{e}}\right) \cdot V}{m}
$$

where $C_{\mathrm{o}}=$ initial sulfur concentration $\left(\mathrm{mg} \mathrm{L}^{-1}\right)$, $C_{\mathrm{e}}=$ equilibrium sulfur concentration $\left(\mathrm{mg} \mathrm{L}^{-1}\right), V$ is the volume (L) of feed diesel, and $m$ is the weight $(\mathrm{g})$ of the adsorbent.

Adsorption isotherm

Isotherm modeling is done to analyze and fit the isotherm data to Langmuir and Freundlich isotherm models to well depict the adsorption process. The Langmuir model is supported on the assumption that the adsorbent surface is uniform with limited adsorption sites and monolayer coverage of adsorbate on it.

The linear form of Langmuir isotherm is represented as

$\frac{C_{\mathrm{e}}}{q_{\mathrm{e}}}=\frac{1}{a b}+\frac{C_{\mathrm{e}}}{a}$

where $C_{\mathrm{e}}=$ equilibrium concentration $\left(\mathrm{mg} \mathrm{L}^{-1}\right)$ of the adsorbate; $q_{\mathrm{e}}=$ amount of adsorbate adsorbed per unit weight of adsorbent $\left(\mathrm{mg} \mathrm{g}^{-1}\right)$; and $a, b$ are Langmuir constants. A linear plot of $C_{\mathrm{e}} / q_{\mathrm{e}}$ versus $C_{\mathrm{e}}$ gives the value of $a\left(\mathrm{mg} \mathrm{g}^{-1}\right)$ from the slope and that of $b\left(\mathrm{~L} \mathrm{~g}^{-1}\right)$ from the intercept.

The Freundlich model represents an isotherm for heterogeneous adsorbent with multilayer exposure of adsorbate on the adsorbent surface. The linear form of the Freundlich isotherm is represented as

$\log q_{\mathrm{e}}=\log k_{\mathrm{F}}+1 / n \log C_{\mathrm{e}}$

where $k_{\mathrm{F}}$ is the Freundlich equilibrium constant illustrating the relative adsorption capacity of the bonding energy 
$\left[\left(\mathrm{mg} \mathrm{g}^{-1}\right) /\left(\mathrm{mg} \mathrm{L}^{-1}\right)^{1 / n}\right]$ and $1 / n$ is an empirical constant correlated with the efficiency of adsorption: $1 / n<1$ signifies the adsorption as favorable, whereas $1 / n>1$ denotes the adsorption process as unfavorable.

\section{Results and discussion \\ Characterization of CICCW}

The adsorptive properties of CICCW were supported by physical and chemical characterization of the adsorbent. The proximate analysis (macro analysis) shows considerably high carbon content, which can be due to the high carbon yield, and the ultimate analysis (microanalysis) of CICCW shows a high carbon and negligible nitrogen content, which is evident from Table 1.

The scanning electron microscope (SEM) images of CICCW under study revealed the characteristic surface morphology of the adsorbent. A scanning electron micrograph of CICCW shown in Fig. 1 depicts a highly heterogeneous surface (irregularity in surface morphology), and the roughness of the surface indicates high surface area for adhering adsorbate molecules, thus favoring adsorption of sulfur from feed diesel. It is evident from the surface texture that the adsorbent is composed of rough heterogeneous sites with randomly oriented pits of several sizes.

The functional groups of CICCW can be better understood from a Fourier transform infrared (FTIR) study of the adsorbent. The spectra can therefore help in interpretation of the functional groups accountable for adsorption. The chemical nature of the adsorbent is put on view by the peaks in the IR spectra (Fig. 2). The FTIR spectrum of CICCW depicts a sharp peak at $3,480 \mathrm{~cm}^{-1}$, which is ascribed to dimeric $\mathrm{OH}$ stretch confirming the existence of a hydroxyl group. Another intense band at $3,400 \mathrm{~cm}^{-1}$ is ascribed to normal polymeric $\mathrm{OH}$ stretch of the hydroxyl group. The band at $1,180 \mathrm{~cm}^{-1}$ corresponds to skeletal vibration of $\mathrm{C}-\mathrm{C}$ stretch, and the peak at $1,580 \mathrm{~cm}^{-1}$ can be ascribed to aromatic ring stretching of $\mathrm{C}=\mathrm{C}-\mathrm{C}$. A progression of weak to moderate absorptions bands $\left(3,150-3,000 \mathrm{~cm}^{-1}\right)$ can be attributed to aromatic $\mathrm{C}-\mathrm{H}$ stretching. FTIR analysis of the spectra showed that the $\mathrm{OH}$ stretching of the hydroxyl group, skeletal vibration of $\mathrm{C}-\mathrm{C}$ stretch, and aromatic $\mathrm{C}-\mathrm{H} \& \mathrm{C}=\mathrm{C}-\mathrm{C}$ stretching may be accountable for sulfur adsorption onto CICCW surface. The carbon surface functionalities of CICCW (Table 1) have been studied by adopting Boehm titration, and the different acidic groups have been computed, which correlates the elucidation from FTIR spectra.

An important characteristic of good adsorbent is their high porosity and larger surface area with more specific adsorption sites (Tein 1994; Linsen 1970). The surface area
Table 1 Physical and chemical characteristics of chemically impregnated coconut coir waste (CICCW)

\begin{tabular}{lrlr}
\hline $\begin{array}{l}\text { Proximate analysis or macro } \\
\text { analysis (wt\% as received) }\end{array}$ & \multicolumn{2}{l}{$\begin{array}{l}\text { Ultimate analysis or } \\
\text { microanalysis (wt\% dry } \\
\text { ash-free basis) }\end{array}$} \\
\hline Moisture & 20.76 & Carbon & 55.53 \\
Volatile matter & 21.78 & Hydrogen & 3.28 \\
Ash & 3.59 & Nitrogen & 0.98 \\
Fixed carbon & 53.87 & Sulfur & 0.00 \\
\hline Functional groups & & & $\begin{array}{l}n_{\mathrm{CSF}} \\
\end{array}$ \\
& & & \multicolumn{2}{c}{$\left.\mathrm{mmol} \mathrm{g}^{-1}\right)$} \\
\hline
\end{tabular}

Carbon surface functionalities on CICCW

a) Acidic groups

Carboxylic

Lactonic

0.057

Phenolic

0.403

b) Basic groups

1.620

Textural Characteristics of CICCW

Surface area of pores $\left(\mathrm{m}^{2} \mathrm{~g}^{-1}\right)$

Single point

BET

BJH

\section{Adsorption cumulative}

Desorption cumulative

Single-point adsorption total pore volume $\left(\mathrm{cm}^{3} \mathrm{~g}^{-1}\right) \quad 1.02$

Average pore diameter (nm)

BET

BJH adsorption

BJH desorption

Typical properties of $\mathrm{CICCW}$

Carbon yield (\%)

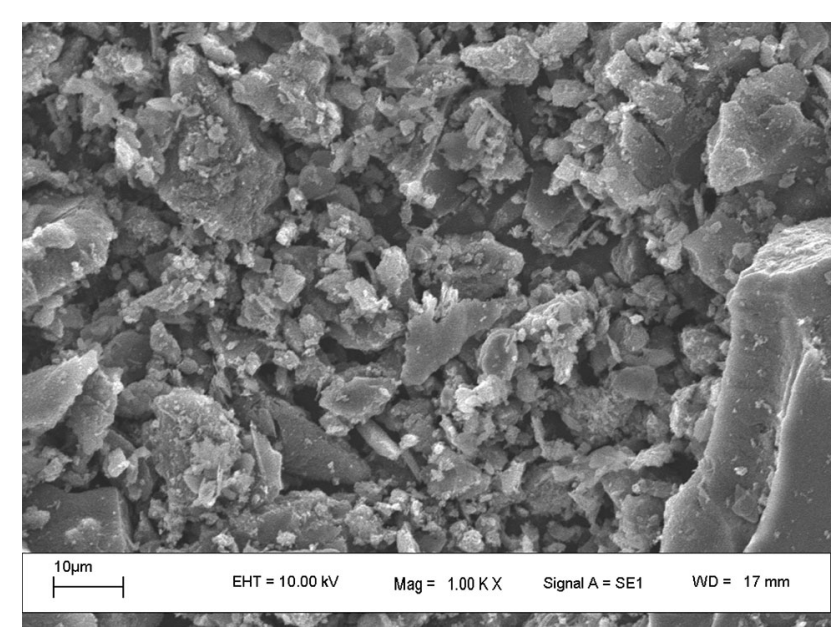

Fig. 1 SEM image of CICCW at $1.00 \mathrm{KX}$ magnification 


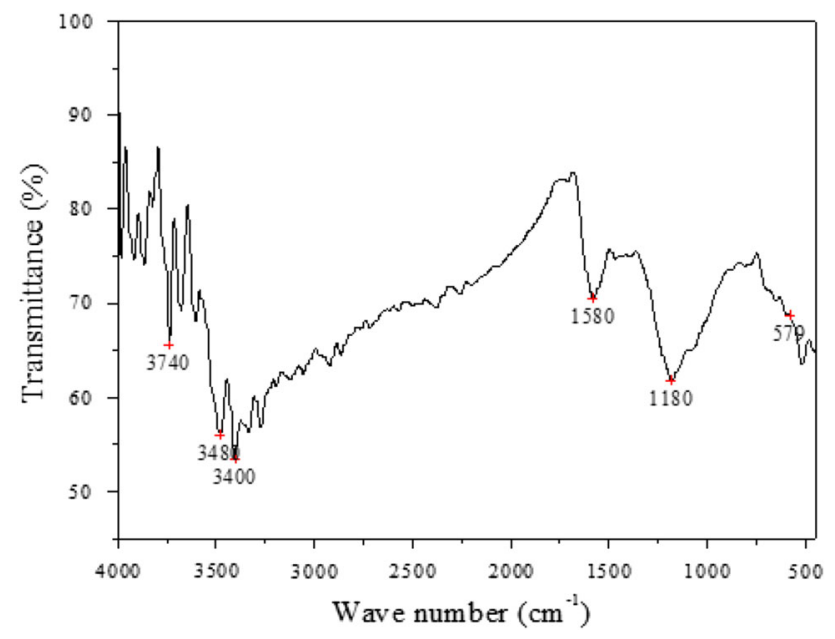

Fig. 2 FTIR spectra of CICCW

of CICCW was calculated from nitrogen adsorption data according to BET model. Textural characteristics of CICCW (Table 1) illustrate the BET, BJH surface area analysis and pore volume distribution. The BET surface area of CICCW was found $1,254.67 \mathrm{~m}^{2} \mathrm{~g}^{-1}$, almost comparable to single-point surface area. The nitrogen adsorption and desorption isotherm plot of CICCW (Fig. 3) showed that the isotherm belong to Type II as defined by IUPAC classification (Greg and Sing 1982; Sing et al. 1985). The internal surface area study is confined to the pore structure of the adsorbent material. The pore structure is also a major factor affecting the adsorption process. If the pore diameter is such that the adsorbate molecules are larger, then lesser adsorption would take place due to steric hindrance. According to the IUPAC classification of pore dimensions, pores are classified as micropore $(\leq 2 \mathrm{~nm})$, mesopore $(2-50 \mathrm{~nm})$, and macropore $(\geq 50 \mathrm{~nm})$. The standard BJH method (Barrett et al. 1951) was applied to determine the pore size distribution curve of CICCW during adsorption and desorption. The $\mathrm{BJH}$ adsorption pore distribution plot of CICCW has been shown in Fig. S1 in the supporting information. The single-point adsorption total pore volume was reported $1.01 \mathrm{~cm}^{3} \mathrm{~g}^{-1}$, which depicts the microporous nature of the adsorbent. The data for pore size of CICCW as determined by BET method were $3.24 \mathrm{~nm}$ in diameter while the adsorption and desorption average pore diameter determined by $\mathrm{BJH}$ method were 4.44 and $3.89 \mathrm{~nm}$, respectively. It indicates that $\mathrm{CICCW}$ has a very narrow pore size distribution. The fraction of pores opened at both ends was found to be nil. The hysteresis loop observed at relatively low pressure in the $\mathrm{N}_{2}$ adsorption and desorption isotherm plot of CICCW indicates small pore size in the mesoporous range (most of them near to micropore range as average pore diameter comes around $3.24 \mathrm{~nm}$ ). The $\mathrm{BJH}$ adsorption pore distribution plot illustrates that the

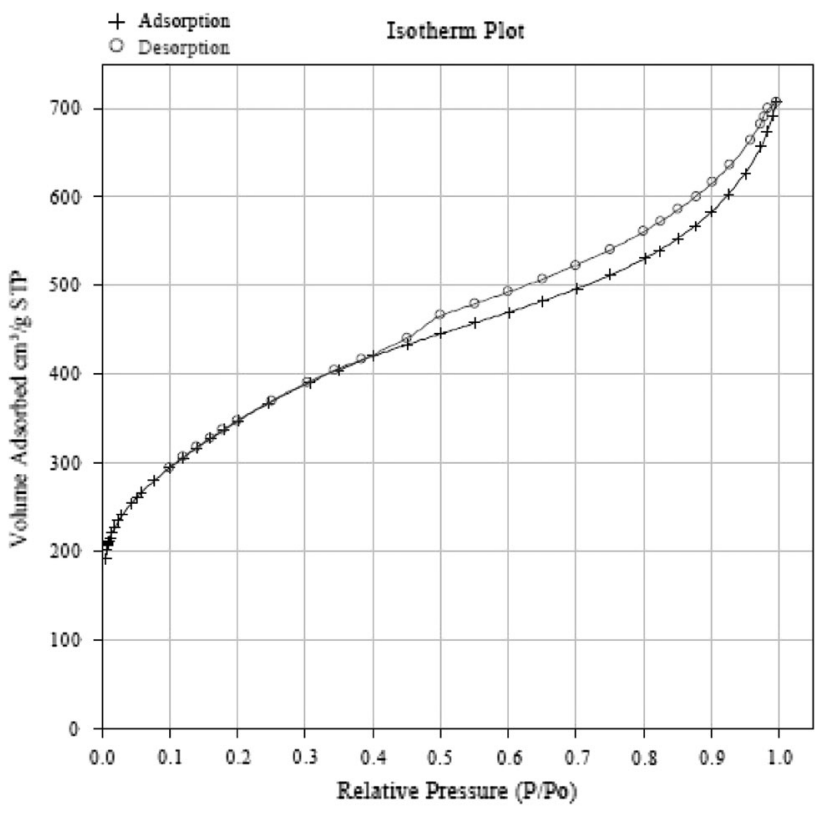

Fig. $3 \mathrm{~N}_{2}$ adsorption and desorption isotherm plot of CICCW

maximum concentration of the pores in the diameter range of $1-15 \mathrm{~nm}$ with average diameter of $3.24 \mathrm{~nm}$. The figure shows that the largest contribution to the total pore volume is contributed by the mesopores followed by certain number of micropore.

\section{Effect of adsorbent loading $(m)$}

The influence of adsorbent load $(m)$ on the removal efficiency was studied by shaking $2,050 \mathrm{mg} \mathrm{L}^{-1}$ feed diesel at $T=293 \mathrm{~K}$. The dose was varied from $0.2-1.2 \mathrm{~g}$. The results are shown in Fig. 4. With the increase in the adsorbent load $(m)$ from 0.2 to $1 \mathrm{~g}$, the $\%$ removal of sulfur increases but showed a marginal change for $m>1 \mathrm{~g}$. The increase in adsorbent load provides accessibility to larger surface area, more adsorption sites, and active functional groups, thereby increasing the adsorptive uptake at initial stage followed by marginal increment at later stage. This is due to the attainment of equilibrium of sulfur concentration at CICCW surface and bulk of the solution at advanced stage. The phenomenon occurring at advanced stage in the adsorption process is known as overcrowding of particles or solid concentration effect (Nowack et al. 1999). Thus, the optimum $m$ of CICCW for sulfur $\left(2,050 \mathrm{mg} \mathrm{L}^{-1}\right)$ was taken as $1 \mathrm{~g} / 20 \mathrm{~mL}$, and further experiments were conducted.

Effect of reaction temperature $(T)$

The effect of reaction temperature on adsorptive capacity of CICCW was studied under optimum conditions and varying the temperature from 293 to $333 \mathrm{~K}$ using 


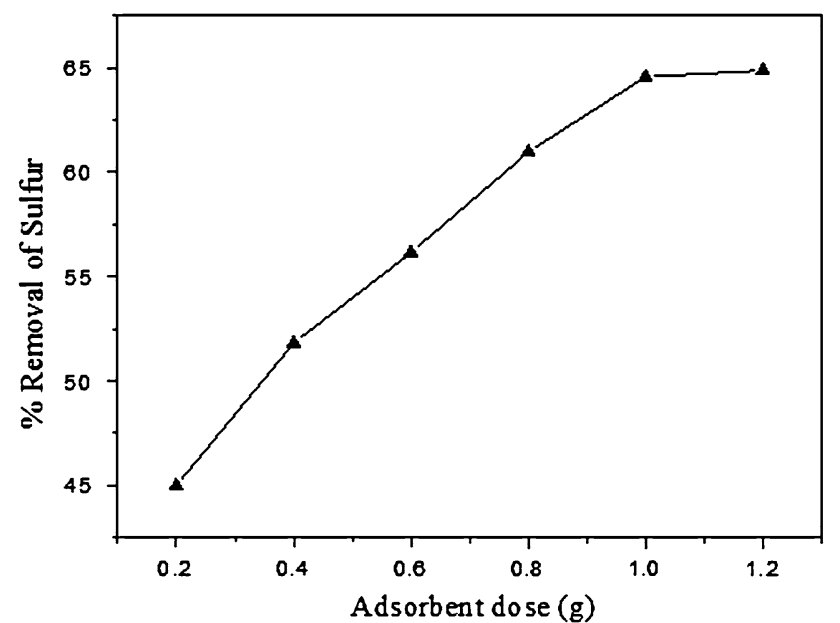

Fig. 4 Effect of adsorbent loading on the ADS of feed diesel by CICCW $\left(C_{\mathrm{o}}=2,050 \mathrm{mg} \mathrm{L}^{-1}, T=293 \mathrm{~K}, t=3 \mathrm{~h}\right)$

$C_{\mathrm{o}}=2,050 \mathrm{mg} \mathrm{L}^{-1}$ of feed diesel. Figure $\mathrm{S} 2$ given in the supporting information portrays the effect of reaction temperature on the adsorption. The optimum temperature of adsorption is reported at $293 \mathrm{~K}$. Temperature study shows that the \% removal of sulfur decreases as temperature increases signifying the exothermic nature of adsorption of sulfur onto CICCW. The weakening of adsorptive forces between the active sites of CICCW and sulfur may be held responsible for the decrease in adsorption capacity with increase in temperature.

\section{Effect of contact time $(t)$}

The experiments were performed with an adsorbent dose of $1 \mathrm{~g}$ with feed diesel at $293 \mathrm{~K}$ for different contact time with the maximum of $5 \mathrm{~h}$. With the lapse of time, the removal of sulfur increases (Fig. 5) and quasi-equilibrium is reached in $3 \mathrm{~h}$. During the first $1 \mathrm{~h}$, the adsorption rate was fast due to the high-concentration gradient between the sulfur molecules in the feed diesel and on the surface of the adsorbent. Therefore, a bulk transport of sulfur molecules from the solution onto the CICCW surface takes place. After $3 \mathrm{~h}$, there is a decrease in the adsorption rate due to more accumulation of sulfur on CICCW surface. This is indicated by the plateau line and become asymptotic after $4 \mathrm{~h}$ signifying that after equilibrium is attained the rate of adsorption equals the rate of desorption.

\section{Diffusion study}

The adsorption behavior, i.e., the transport of adsorbate from the solution to the surface of the adsorbent, takes place in one or more steps, or by a combination of steps viz. surface diffusion, pore diffusion, external diffusion, and adsorption on the pore surface. Weber-Morris plot

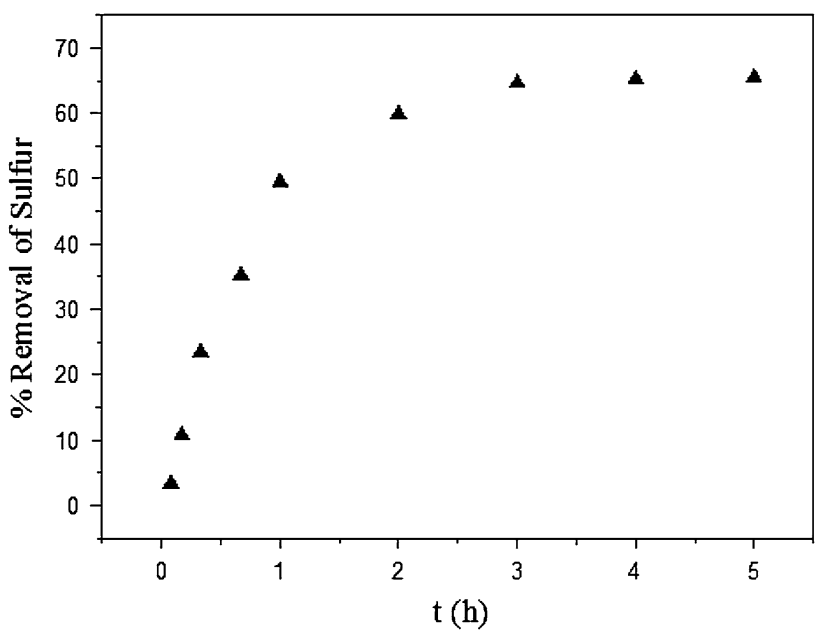

Fig. 5 Effect of contact time on the ADS of feed diesel by CICCW $\left(C_{\mathrm{o}}=2,050 \mathrm{mg} \mathrm{L}^{-1}, T=293 \mathrm{~K}, m=1 \mathrm{~g}\right)$

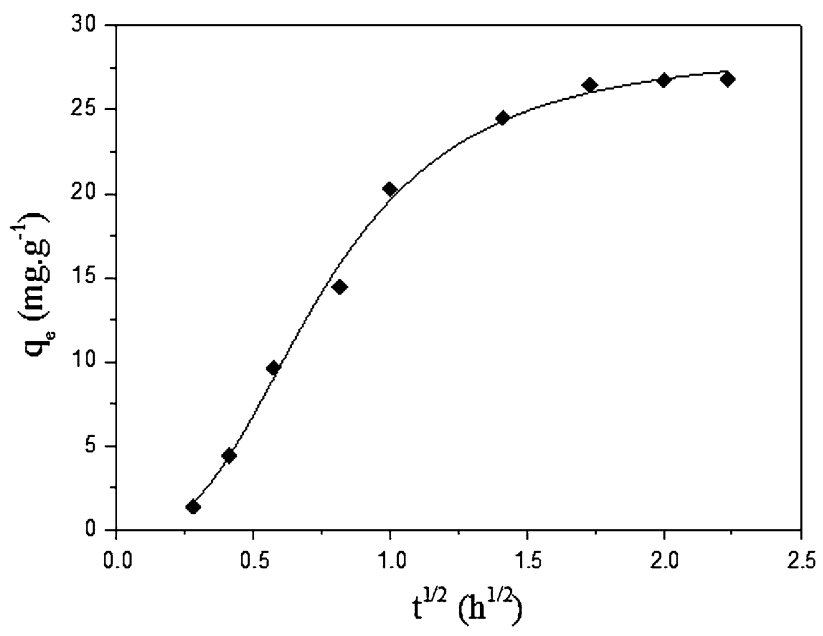

Fig. 6 Weber and Morris intra-particle diffusion plot for ADS of feed diesel by CICCW $\left(C_{\mathrm{o}}=2,050 \mathrm{mg} \mathrm{L}^{-1}, m=1 \mathrm{~g}, T=293 \mathrm{~K}\right)$

(Bhattacharya and Venkobachar 1984) $\left(q_{\mathrm{e}}\right.$ vs. $\left.t^{1 / 2}\right)$ is generally used to depict whether the adsorption process is controlled by an intra-particle diffusion model (Allen et al. 1989). A straight line of the plot reveals the intra-particle diffusion behavior of adsorption. Nevertheless, the data in the present study do not exhibit a linear plot over the whole range of time, demonstrating that more than one step is controlling the adsorption process. The plot of $q_{\mathrm{e}}$ versus $t^{1 / 2}$ (Fig. 6) for sulfur adsorption from feed diesel onto CICCW at $T=293 \mathrm{~K}$ reveals that the adsorption of sulfur onto CICCW is controlled by external mass transfer followed by intra-particle diffusion. It can be inferred from WeberMorris plot of CICCW that at the start of the adsorption process the diffusion of sulfur molecules from the solution to the external surface of the adsorbent is the fastest, which can be ascribed to the fast utilization of readily available 
active sites on the adsorbent surface. The first sharp part of the plot signifies external surface adsorption by mesopore diffusion, the second curved section shows gradual adsorption stage (rate-limiting step) by intra-particle diffusion into micropores, and the final almost linear segment is the equilibrium phase, where rate of adsorption diminishes owing to very low sulfur concentration. The pore diffusion coefficient, $D$, for the exclusion of sulfur has been computed using Eq. 8, assuming spherical shape geometry for the adsorbent (Ahmed et al. 2014).

$t^{1 / 2}=0.03 r_{\mathrm{o}}^{2} / D$

where $t^{1 / 2}$ is the time for the half adsorption; $r_{\mathrm{o}}$ is the diameter of the adsorbent particles, i.e., $33.354 \times$ $10^{-4} \mathrm{~cm}$; and $D$ is the pore diffusion constant, $\mathrm{cm}^{2} \mathrm{~s}^{-1}$. The value of the pore diffusion coefficient of sulfur was found $6.18 \times 10^{-11} \mathrm{~cm}^{2} \mathrm{~s}^{-1}$, indicating pore diffusion is not significant. To have knowledge of the mode of diffusion, the transport number was calculated from Eq. 9 (Ahmed et al. 2014)

$\log Q_{t} / Q_{\infty}=\log k+n \log t$

where $Q_{t}$ and $Q_{\infty}$ is the weight of the adsorbate with adsorbent at time $t$ and equilibrium, respectively; $k=$ adsorbate-adsorbent interaction coefficient; $n=$ transport number; and $t=$ time. The transport number ( $n=0.096)$ and value of $k$ were obtained from the slope and intercept of the plot of $\log Q_{t} / Q_{\infty}$ versus $\log t$ (plot not shown), respectively.

The value of $n$ is indicative of the type of transport mechanism involved in the diffusion phenomena. A value of $n \leq 0.5$ portrays a Fickian mechanism, whereas $n \geq 1$ depicts a non-Fickian mechanism. In the present study, the calculated transport number $(n<0.5)$ portrays a Fickian mechanism of diffusion of sulfur onto CICCW.

\section{Adsorption isotherm}

Adsorption isotherm is imperative for the illustration of the interaction of the active sites of the adsorbent with the adsorbate and is significant in adsorbent optimization. The experimental data in this study are correlated with Langmuir and Freundlich isotherm models. An important step in isotherm modeling is to analysis and fit the isotherm data to different isotherm models to well depict the adsorption process. The linear regression analysis of Freundlich adsorption parameters shows a significantly high $R^{2}$ value (0.977) representing a good fit to the model. However, the linear regression coefficient value shows that the Langmuir isotherm fits the experimental data, but Langmuir isotherm is derived with the assumption that the surface of the adsorbent is homogeneous, which contradicts with the highly heterogeneous surface of CICCW as shown in

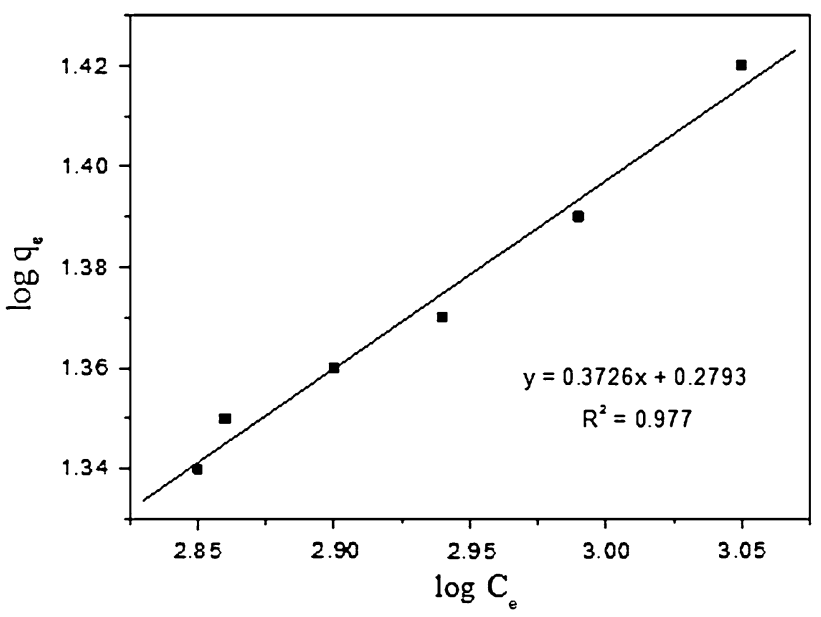

Fig. 7 Freundlich isotherm for adsorption of sulfur from feed diesel by $\operatorname{CICCW}\left(C_{\mathrm{o}}=2,050 \mathrm{mg} \mathrm{L}^{-1}, T=293 \mathrm{~K}, t=3 \mathrm{~h}\right)$

the SEM micrograph. That is why the Langmuir isotherm and the corresponding adsorption parameters are not shown. Nevertheless, the Langmuir isotherm is also utilized to estimate maximum adsorption capacity, $q_{\mathrm{e}}$, widely used to compare the quality of different adsorbents. Fig. 7 shows the Freundlich isotherm for the adsorbent, CICCW prepared in this work. The figure clearly shows that the adsorption data can be represented by Freundlich isotherm accurately within the experimental conditions investigated. The isotherm parameters for Freundlich isotherm are calculated from the graph. The relative adsorption capacity of the bonding energy of CICCW, $K_{\mathrm{F}}=1.90$, and the value of the empirical constant $1 / n$ related to adsorption efficiency was found to be 0.3726 . This indicates that the adsorption of sulfur onto CICCW is favorable as the value of $1 / n<1$.

\section{Adsorption thermodynamics}

The standard change in Gibbs free energy $\left(\Delta G^{\circ}\right)$, enthalpy $\left(\Delta H^{\circ}\right)$, and entropy $\left(\Delta S^{\circ}\right)$ associated with adsorption was obtained from the experiments performed at different temperatures $(293,303$, and $313 \mathrm{~K})$ and calculated with the help of the following equations (Khan et al. 1995).

$K_{\mathrm{ad}}=C_{s} / C_{\mathrm{e}}$

$\Delta G^{\circ}=\Delta H^{\circ}-T \Delta S^{\circ}$

The standard enthalpy change $\left(\Delta H^{\circ}\right)$ and standard entropy change $\left(\Delta S^{\circ}\right)$ of adsorption can be calculated from van't Hoff equation

$\ln K_{\mathrm{ad}}=-\frac{\Delta H^{\circ}}{R T}+\frac{\Delta S^{\circ}}{R}$

where $K_{\text {ad }}$ is the equilibrium adsorption constant, $C_{\mathrm{e}}$ is the equilibrium sulfur concentration $\left(\mathrm{mg} \mathrm{L}^{-1}\right)$ in feed diesel, 


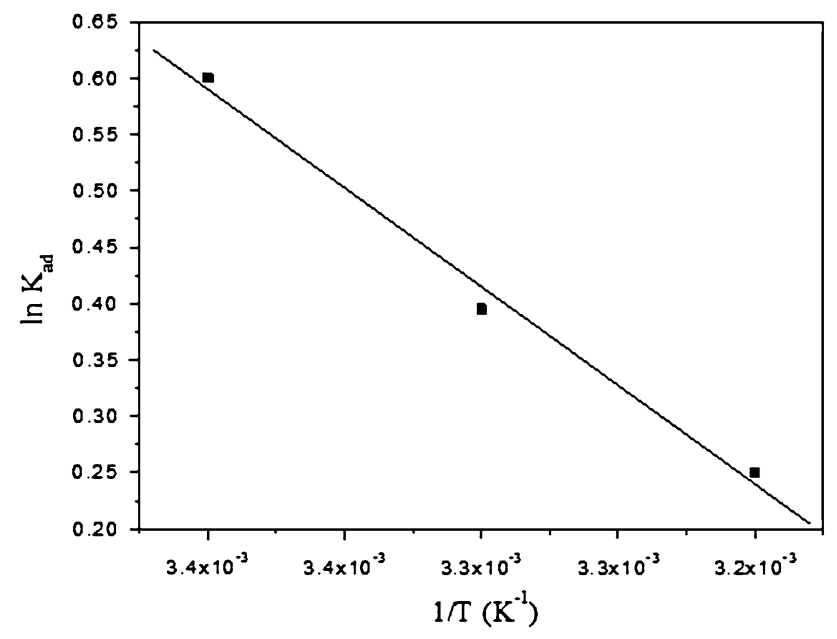

Fig. 8 van't Hoff plot of adsorption equilibrium constant $K_{\mathrm{ad}}$ for ADS of feed diesel by CICCW $\left(C_{\mathrm{o}}=2,050 \mathrm{mg} \mathrm{L}^{-1}, m=1 \mathrm{~g}\right.$, $t=3 \mathrm{~h}$ )

and $C_{s}$ is the equilibrium solid phase sulfur concentration ( $\mathrm{mg} \mathrm{L}^{-1}$ ), i.e., the mass of sulfur adsorbed at equilibrium. $K_{\text {ad }}$ is defined as the ratio of mass per unit sulfur adsorbed to the equilibrium concentration of sulfur per unit volume of feed diesel. The plot of $\ln K_{\text {ad }}$ versus $1 /$ T (Fig. 8) gives the value of $\Delta H^{\circ}$ from the slope $\left(-\Delta H^{\circ} / R\right)$ and the value of $\Delta S^{\circ}$ from intercept $\left(\Delta S^{\circ} / R\right)$, and their respective values were calculated using Eq. 12. The calculated values of $\Delta H^{\circ}$ and $\Delta S^{\circ}$ are found to be $-14.55 \mathrm{~kJ} \mathrm{~mol}^{-1}$ and $-44.56 \mathrm{~J} \mathrm{~K}^{-1} \mathrm{~mol}^{-1}$, respectively. The corresponding value of $\Delta G^{\circ}$ is calculated as $-27.61,-28.05$, and $-28.49 \mathrm{~kJ} \mathrm{~mol}^{-1}$ at 293,303 , and $313 \mathrm{~K}$, respectively, by substituting the values of $\Delta H^{\circ}$ and $\Delta S^{\circ}$ in Eq. 11. The negative value of $\Delta H^{\circ}$ corroborates the exothermic nature of adsorption. In physisorption process, the adsorbate and adsorbent are held together by weak van der Walls force of attraction, and the adsorption energy is typically $5-10 \mathrm{~kJ} \mathrm{~mol}^{-1}$. In chemisorption, there exist a chemical bond between the adsorbate and the adsorbent having adsorption energy of 30-70 $\mathrm{kJ} \mathrm{mol}^{-1}$ (Murzin and Salami 2005). Therefore, the adsorption of sulfur onto CICCW seems to be physisorptive in nature. The negative value of $\Delta S^{\circ}$ signifies a decrease in the randomness of sulfur molecules at the solid/solution interface. Moreover, it shows an affinity of the sulfur molecules toward CICCW. A decrease in Gibbs free energy, $\Delta G^{\circ}$, value being negative signifies the spontaneity and feasibility of the adsorption process.

Regeneration and reusability studies with exhausted adsorbent

Due to growing concern for waste minimization, recovery, and reuse as well as for industrial applications, the regeneration performance of sulfur loaded adsorbent was investigated. The exhausted adsorbent (CICCW) with loaded sulfur was regenerated by using methanol as the extracting solvent. Experimental runs were performed with $1 \mathrm{~g}$ of sulfur loaded CICCW and $20 \mathrm{~mL}$ of methanol, subjected to vigorous stirring in a $100 \mathrm{~mL}$ stoppered Erlenmeyer flask at $303 \mathrm{~K}$ for $2 \mathrm{~h}$. The resulting mixture was filtered, and the filtrate was analyzed for sulfur concentration as stated earlier. The regenerated adsorbent was again explored for reusability studies by following the adsorption-desorption cycles for three runs, and the sulfur removal efficiency in each run was computed. Regenerated adsorbent shows sulfur removal efficiency of 63.29, 58.77, and $56.18 \%$ in successive runs in comparison with $\sim 65 \%$ for the fresh CICCW. This shows that 98.04, 91.01, and $86.98 \%$ of the original adsorption capacity were retained by the regenerated adsorbent in three runs, respectively.

\section{Comparison of adsorption efficiency of CICCW} with commercial activated carbon

To acquire better knowledge of the adsorption capacities of the candidate adsorbent (CICCW) for the uptake of sulfur from feed diesel, the present study focuses on comparison of adsorptive removal with CAC. It needs to be mentioned that so far commercial activated carbon has not been explored for the desulfurization of feed diesel (from refineries) particularly with high sulfur concentration of $2,050 \mathrm{mg} \mathrm{L}^{-1}$. Hence, a direct comparison on adsorption efficiency could not be done. However, the efficiency of CAC has been explored by many researchers for the desulfurization of model diesel with low sulfur concentrations (max. $500 \mathrm{mg} \mathrm{L}^{-1}$ ) for BT, DBT, and DMDBT. Thus, it is noteworthy to portray that in this study the utility of CICCW was explored for a very high concentration of feed diesel (with no reference reported in literature), attained a quick equilibrium at $3 \mathrm{~h}$ and an average removal of $\sim 65 \%$. The easy regeneration technique and good reusability performance add to the desirability of the adsorbent for desulfurization of feed diesel.

\section{Cost evaluation of CICCW}

Cost analysis is a vital stricture in establishing the criteria for utility of the adsorbent and the choice of treatment process for environmental remediation. The costs incurred on ADS of feed diesel largely depend on the cost of CICCW. The choice of an activated carbon depends on cost in addition to performance. The utilization of waste materials to produce activated carbon for environmental remediation is of significant economic potentiality and can substitute commercial activated carbon (CAC). The market rate of $\mathrm{CAC}$ is around USD 172.96 per $\mathrm{kg}$ (Merck, 
Table 2 Cost estimation for preparation of $1 \mathrm{~kg}$ of the adsorbent (CICCW)

\begin{tabular}{lclll}
\hline Breakup cost & $\begin{array}{l}\text { Duration (h)/ } \\
\text { amount (ml) }\end{array}$ & $\begin{array}{l}\text { Unit cost } \\
\text { (USD) }\end{array}$ & $\begin{array}{l}\text { Power } \\
\text { rating } \\
\text { (KWh) }\end{array}$ & $\begin{array}{l}\text { Price } \\
\text { (USD) }\end{array}$ \\
\hline $\begin{array}{l}\text { Cost of drying at } \\
\text { oven }\end{array}$ & 5 & 0.0664 & 1.5 & 0.498 \\
$\begin{array}{l}\text { Cost of } \\
\text { impregnation at } \\
\text { hot plate }\end{array}$ & 1 & 0.0664 & 1.2 & 0.079 \\
$\begin{array}{l}\text { Cost of activation } \\
\text { at furnace }\end{array}$ & 1 & 0.0664 & 2.5 & 0.166 \\
$\begin{array}{l}\text { Cost of final } \\
\text { drying at oven }\end{array}$ & 6 & 0.0664 & 1.5 & 0.597 \\
$\begin{array}{l}\text { Cost of } \mathrm{H}_{3} \mathrm{PO} \\
\text { used }\end{array}$ & 500 & 0.0168 & - & 8.4 \\
$\begin{array}{l}\text { Net cost } \\
\text { Overhead cost } \\
\text { (10 \% of net } \\
\text { cost) }\end{array}$ & & & & 9.74 \\
\begin{tabular}{l} 
Total cost \\
\hline
\end{tabular} & & & & 0.974 \\
\end{tabular}

Charcoal activated, pure), whereas the total cost incurred in the preparation of CICCW is USD 10.714 per $\mathrm{kg}$. Table 2 shows the breakup cost estimation (Ahmed et al. 2014) of CICCW used in the present study. Due to the local availability of the agricultural waste, the transportation cost is negligible. The cost of storage is also eliminated as the adsorbent is mostly stable under high temperature or pressure. These signify that in comparison with commercial activated carbon, CICCW is much cheaper and its exploitation for ADS of feed diesel is quite justified.

\section{Conclusion}

The present study demonstrates that chemically impregnated coconut coir waste (CICCW) can be effectively used for the desulfurization of feed diesel. Extensive characterization of the adsorbent revealed that it has most of the desirable qualities of a good low-cost adsorbent. An optimum adsorbent dose of $1 \mathrm{~g}$ and optimum temperature of $293 \mathrm{~K}$ show maximum adsorption. Equilibrium between the feed diesel and the adsorbent almost attains in $3 \mathrm{~h}$. Multistage diffusion model explains the process of adsorption. External mass transfer controls the adsorption of sulfur at initial phase followed by intra-particle diffusion. The mechanism of adsorption of sulfur onto CICCW follows a Fickian mechanism of diffusion. Freundlich model best fits the experimental data $\left(R^{2}=0.9907\right)$, signifying heterogeneous adsorption and multilayer coverage of the adsorbate (sulfur) on the surface of CICCW. Thermodynamic data revealed the exothermic nature of the adsorption process, and hence, the adsorption of sulfur decreases with increase in temperature. The decline in the randomness of sulfur molecules on the adsorbent surface post-adsorption is confirmed by the negative value of $\Delta S^{\circ}$. The spontaneity and feasibility of adsorption are confirmed from the negative value of $\Delta G^{\circ}$. The regeneration of exhausted adsorbent by methanol and its utilization for three adsorption-desorption cycles further add to the economic utilization of CICCW. The total cost involved in the preparation of CICCW is USD 7.25 per kg, which is very less in comparison with the cost of commercial activated carbon. The results demonstrated that CICCW may be effectively utilized in the adsorptive desulfurization of feed diesel for a better environmental friendly technique in petroleum refining.

Acknowledgments The authors are thankful to Director, National Institute of Technology Silchar and Indian Oil Corporation Limited. (IOCL), Guwahati refinery for providing laboratory facilities for accomplishing the work. Special thanks to Dr. Ashutosh Mishra (SQC Officer, IOCL) for helping in XRF analysis of feed diesel sample for sulfur concentration. The authors are also thankful to anonymous reviewers for their valuable comments in upgrading the quality of the manuscript.

\section{References}

Achmann S, Hagen G, Hammerle M, Malkowsky I, Kiener C, Moos R (2010) Sulfur removal from low-sulfur gasoline and diesel fuel by metal-organic frameworks. Chem Eng Technol 33:275-280

Ahmed Md JK, Ahmaruzzaman M, Reza RA (2014) Lignocellulosicderived modified agricultural waste: development, characterisation and implementation in sequestering pyridine from aqueous phase. J Colloid Interface Sci 428:222-234

Allen SJ, McKay G, Khader KYH (1989) Intraparticle diffusion of a basic dye during adsorption onto sphagnum peat. Environ Pollut 56:39-50

Babich IV, Moulijn JA (2003) Science and technology of novel processes for deep desulfurization of oil refinery streams: a review. Fuel 82:607-631

Barrett EP, Joyner LG, Halenda PP (1951) The determination of pore volume and area distributions in porous substances. I. Computations from nitrogen isotherms. J Am Chem Soc 73:373-380

Bhattacharya AK, Venkobachar C (1984) Removal of cadmium(II) by low-cost adsorbents. J Environ Eng 110:110-122

Boehm HP (1996) Chemical identification of surface groups. In: Eley DD, Pines H, Weisz PB (eds) Advances in catalyses and related subjects, vol 16. Academic Press, New York, pp 179-274

Brunauer S, Emmett PH, Teller E (1938) Adsorption of gases in multimolecular layers. J Am Chem Soc 60:309-319

Fallah RN, Azizian S (2012) Rapid and facile desulphurization of liquid fuel by carbon nanoparticles dispersed in aqueous phase. Fuel 95:93-96

Fallah RN, Azizian S (2014) Removal of thiophenic compounds from liquid fuel by different modified activated carbon cloths. Fuel 93:45-52

Greg SJ, Sing KSW (1982) Adsorption, surface area and porosity. Academic Press, London

Jagtoyen M, Derbyshire F (1993) Some considerations of the origins of porosity in carbons from chemically activated wood. Carbon $32: 1185-1192$ 
Jiang Z, Liu Y, Sun X, Shen Z, Han C, Li C (2003) Adsorption of dibenzothiophene on modified activated carbons for ultra-deep desulfurization of fuel oils. Chin J Catal 24:649-650

Khan NA, Jhung SH (2013) Effect of central metal ions of analogous metal-organic frameworks on the adsorptive removal of benzothiophene from a model fuel. J Hazard Mater 260:1050-1056

Khan SA, Rehman R, Khan MA (1995) Adsorption of Cr(III), Cr(VI) and $\operatorname{Ag}(\mathrm{I})$ on Bentonite. Waste Manag 15:271-282

Laredo GC, Vega-Merino PM, Trejo-Zarraga F, Castillo J (2013) Denitrogenation of middle distillates using adsorbent materials towards ULSD production: a review. Fuel Proc Technol 106:21-32

Linsen BG (1970) Physical and chemical aspects of adsorbents and catalyst. Academic Press, London

Murzin D, Salami T (2005) Chemical kinetics. Elsevier, Amsterdam

Nowack KO, Cannon FS, Arora H (1999) Ferric chloride plus GAC for removing TOC. J Am Water Works Assoc 91:65-78

Park JG, Ko CH, Yi KB et al (2008) Reactive adsorption of sulfur compounds in diesel on nickel supported on mesoporous silica. App Catal B Environ 81:244-250

Sarah LG, Kim DT, Alicia MD, Anthony CT, Heather AA (2010) Standardization of Boehm titration. Part $\mathrm{I} \mathrm{CO}_{2}$ expulsion and end point determination. Carbon 48:1252-1261

Sarda KK, Bhandari A, Pant KK, Jain S (2012) Deep desulfurization of diesel fuel by selective adsorption over $\mathrm{Ni} / \mathrm{Al} 2 \mathrm{O} 3$ and $\mathrm{Ni} /$ ZSM-5 extrudates. Fuel 93:86-91

Sing KSW, Everett DH, Haul RAW et al (1985) Reporting physisorption data for gas/solid systems with special reference to the determination of surface area and porosity. Pure Appl Chem 57:603-619

Song C (2002) Fuel processing for low-temperature and hightemperature fuel cells: challenges, and opportunities for sustainable development in the 21st century. Catal Today 77:17-49

Subhan F, Liu BS (2011) Acidic sites and deep desulfurization performance of nickel supported mesoporous AIMCM-41 sorbent. Chem Eng J 178:69-77

Tein C (1994) Adsorption calculations and modelling. ButterworthHeinemann, Boston

Triantafyllidis KS, Deliyanni EA (2014) Desulfurization of diesel fuels: adsorption of 4,6-DMDBT on different origin and surface chemistry nanoporous activated carbons. Chem Eng J 236: 406-414

Whitehurst DD, Knudsen KG, Wiwel P, Zeuthen P (2000) The influence of trace amounts of nitrogen compounds on the achievement of future sulfur specifications in diesel fuels-Part 2: HDS inhibition studies with real feeds and isolated N-compound fractions. Am Chem Soc Div Petrol Chem 45:367-370

Xiao J, Li Z, Liu B, Xia Q, Yu M (2008) Adsorption of benzothiophene and dibenzothiophene on ion-impregnated activated carbons and ion-exchanged $\mathrm{Y}$ zeolites. Energy Fuels 22:3858-3863

Zhao L, Chen Y, Gao J, Chen Y (2010) Desulfurization mechanism of FCC gasoline: a review. Front Chem Eng China 4:314-321

Zhou A, Ma X, Song C (2009) Effects of oxidative modification of carbon surface on the adsorption of sulfur compounds in diesel fuel. Appl Catal B Environ 87:190-199 